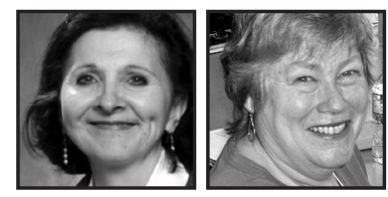

\title{
Arts-Informed Narrative Inquiry: Crossing Boundaries of Research and Teaching-Learning
}

\author{
Jasna Krmpotić Schwind, Ryerson University
}

Gail M. Lindsay, University of Ontario Institute of Technology

\begin{abstract}
Creative engagement accesses profound knowing and understanding that is not reachable by words alone. Situated in Connelly and Clandinin's Narrative Inquiry, we use creative self-expression in teaching-learning, research, and practice. We examine artful approaches used in research with students and nurses in mental health, and in our classrooms. Through such artful inquiry we push the boundaries of what it means to co-create knowledge. Our students, future caregivers, learn how knowing has both epistemological and ontological dimensions. In our experience, it is embodied knowing that has the greatest potential for making connections with those in our care.
\end{abstract}

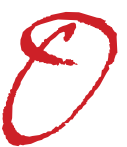

ur research approach, using the arts, is informed by our research methodology of Narrative Inquiry (Connelly \& Clandinin, 1990, 2006), Dewey's (1938) philosophy that experience is education, and our own respective research programs (Lindsay, 2005, 2006, 2008, 2011; Lindsay \& Smith, 2003; Schwind, 2003, 2008, 2014, 2016). Foregrounding the way we reconstruct experience through the arts to access tacit knowing (Polanyi, 1966/2009; Schwind, 2003), we call our method Arts-Informed Narrative Inquiry (AINI) (Lindsay \& Schwind, 2014a, 2015; Schwind, Lindsay, Coffey, Morrison, \& Mildon, 2014). The purpose of this article is to describe and to reflect upon the creative self-expression approaches we use, thereby showing how artful inquiry matters to research-informed nursing education. To illustrate how we use AINI to co-construct and expand knowledge in healthcare education and practice, we first present an exemplar of a two-phase inquiry into 
person-centred care in mental health practice. Next, we examine artful inquiry practices in teaching-learning such that students are encouraged to be creatively engaged to transform their understanding and thus be intellectually responsible, asking for "the meaning of what they learn, in the sense of what difference it makes to the rest of their beliefs and actions" (Dewey, 1933/1998, p. 33). Through such artful inquiry we push the boundaries of what it means to co-create knowledge. Our students, future caregivers, learn how knowing has epistemological as well as ontological dimensions, both of which are necessary to provide person-centred care, which also includes the caregiver. However, in our experience, it is embodied knowing that has the greatest potential to bring forth the connection with those in our care.

\section{Research Process}

Challenging the boundaries of what is commonly understood as patient-centred care in nursing (RNAO, 2015), as narrative inquirers, we wondered how students and practicing nurses in mental health conceptualize and enact person-centred care. In phase one of the inquiry (Schwind et al., 2014), we met with third-year undergraduate nursing students and nurses together for four half-day sessions. During our time together we engaged in creative activities and reflective dialogue that included the creation of a lifeline, metaphoric reflection, construction of a collage, and co-creation of art to music. Out of this research we created a resource website (Lindsay \& Schwind, 2014b), which students, practitioners, and educators around the world, who want to increase self-awareness and deepen personal knowing, can access to engage in creative self-expression activities, individually or in small groups, at their convenience. Subsequently, in phase two of our inquiry (Lindsay \& Schwind, 2015), we explored person-centred care with nurses in mental health who were implementing a new relationship-based delivery model of care on two pilot units. During this inquiry phase, we met in person with the participants for three sessions (1,3, and 5), and two independent online sessions ( 2 and 4 ), using our website. At this time we also added another creative activity: mindful movement and mandalas.

As the purpose of this article is to describe and reflect upon the artful inquiry we use, we examine below each of the above-identified activities: 


\section{Lifeline}

As an introductory step into the creative process, we invite participants during the first session to begin to turn their gaze inwards and to reflect on their life experiences. We provide the participants with large pieces of paper and crayons with the following instructions: Draw your lifeline and identify, significant to you, life experiences. Note the personal events below the line, and professional events above the line. The reason we specify the personal events to be noted below the line is rooted in the philosophical view of the Narrative Inquiry approach. Namely, who we are as persons is who we are as professionals (Lindsay, 2008). In other words, our personal life experiences, which began before our professional roles, inform our professional lives. Polanyi's (1958/1974) thinking aligns with our own view on the significance of personal knowing within professional contexts. He writes, "into every act of knowing there enters a passionate contribution of the person knowing what is being known, and that this co-efficient is no mere imperfection, but a vital component of his knowledge" (p. viii). However, as the lifeline progresses, we find the reciprocity between our personal and professional lives strengthens, where they become mutually informing. Following the drawing activity, we ask the participants to write stories about their significant life events in the journals provided.

The lifeline is an exercise we originally engaged in as graduate students to enter into our own inquiry through reflection on our life experiences, exploring narrative patterns that play out in the present moment (Clandinin \& Connelly, 1998). This intentional reflection on experience is informed by Dewey's (1938) notion that, "without some reconstruction, some remaking" (p. 64) of our life experiences there is no intellectual evolution. By making meaning of emerging narrative patterns, we deepen our personal knowing (Carper, 1978) and so create opportunity for more informed choices for future actions. We bring this knowing forward into our teaching-learning and research.

We find that participants engaging in creative self-expression are often reticent and may quickly shy away if any judgment is perceived. Thus, we inform them that there are no right or wrong ways of doing this or other creative activities throughout the inquiry process, and that whatever they create is right for them at that moment. We caringly repeat this statement throughout each of the sessions we are with our participants, and in the classroom with our students.

Another significant part of our creative work is that each activity is followed by individual reflection on what was meaningful to them and what, if anything, they learned through the process. This is usually followed by an invitation to share the creative activity and reflection with another person in the group. As participants 
become more comfortable with one another, we invite a group reflective dialogue, stipulating to share only what participants feel comfortable sharing.

\section{Metaphoric Reflection}

Following the lifeline activity, at a subsequent session, we invite the participants to engage in metaphoric reflection, which is part of a multi-step creative self-expression activity, namely the Narrative Reflective Process (Schwind, 2008, 2014, 2016), often used in other teaching-learning-research and professional development contexts (Schwind, Cameron, Franks, Graham, \& Robinson, 2012; Schwind, Fredericks, Metersky, \& Gaudite Porzuczek, 2015; Schwind, Santa Mina, Metersky, \& Patterson, 2015). Metaphoric reflection is done individually, with progressive sharing and dialogue with group members. We invite the participants to choose a metaphor that best represents for them a particular phenomenon and then to draw it. In this exemplar we focus on person-centred care. Creative engagement, such as metaphor and drawing, surface parts of us not reachable by words alone (Schwind, 2003). Through drawing we begin to discern relationships by the way we situate lines in space (Bennett, 2010), and so deepen the understanding of how the chosen metaphor reveals personal knowing. Such artful expression ought to "expand perception, inspire focused participatory dialogue, [all the while] considering the question, Does the metaphor make felt qualitative meaning more accessible?" (Faulkner, 2009, p. 89).

In this particular exercise, we are often met with self-conscious comments from the participants about not being "artists." We continue to gently reassure the participants that whatever they draw is right for them. Following the drawing and the sharing, we invite the participants to have their metaphor write them a letter. This too is often met with puzzled looks and chuckles. However, after further elaboration on the request, participants are directed to a table filled with varied design stationery, and to choose one they want for their letter. A quiet energy then fills the space, as everyone enters into their own creation. Below is an example of one such letter:

Dear Self (from the chosen metaphor computer), I am here to provide answers to your questions.

The answers may not be easier to access, but it is there; do not give up.

I'll provide more than one perspective for you to choose the best suitable answer for your questions.

You can take me anywhere, just do not forget my charger.

You can ask me anything, I will not judge.

In order for me to help you, you have to help me as well, keep me updated. 
Not only do I provide information, I store things too.

These things will only be released when you tell me to.

I do not sleep, I note but do not follow time.

Be delicate and I will last forever.

Remember everyone makes mistakes, it is all about how you learn. (February 9, 2013)

In the same session, and following the metaphoric reflection, participants are invited to review the earlier creative activities, the lifeline (their stories of their life events), any reflective writing on their experiences of engaging in creative activities, and the metaphor letter. As they read and re-read these pieces of writing and re-look at the images, participants are asked to highlight what is meaningful to them, such as words, repeating phrases, and any other significant aspects of the images. Using these words they create a poem that speaks to how they conceptualize person-centred care. Such a poetic creation has been referred to in literature as "found poetry" (Bhattacharaya, 2008; Butler-Kisber, 2002; Prendergast, 2006), and serves to distil the essence of one's experience, revealing the author's values, hopes, and dreams.

\author{
People are intricate layers of thought and feelings \\ Acknowledgement of this is important to these beings \\ Change, need and loss are life's continuous cost \\ Personalized care to help transition \\ Restores ability, growth, and adaptation \\ Change to the positive \\ Precedes endless possibilities. (February 9, 2013)
}

\title{
Collage
}

In session three we expand reflection and explicitly include the environment within which participants live, study, and work. This creative activity requires moving from inside of self (personal values and beliefs, accessed through metaphoric reflection and poem writing) and moving outward to consider the context within which they experience the phenomenon being explored. This activity, which involves social and extroverted aspects of human behavior, also requires rumination. Each participant is given a large poster paper, and the table in the centre of the room is covered with all sorts of collage-making materials (Fig. 1). This activity is usually filled with a soft hum of thinking out loud, as well as energetic exclamations at catching sight of a neighbor's creation. As a form of visual inquiry, "collage evokes embodied responses, and uses the juxtaposition of fragments and the presence of ambiguity to engage the viewer in multiple avenues of interpretation" (Butler-Kisber, 2010, p. 102). 


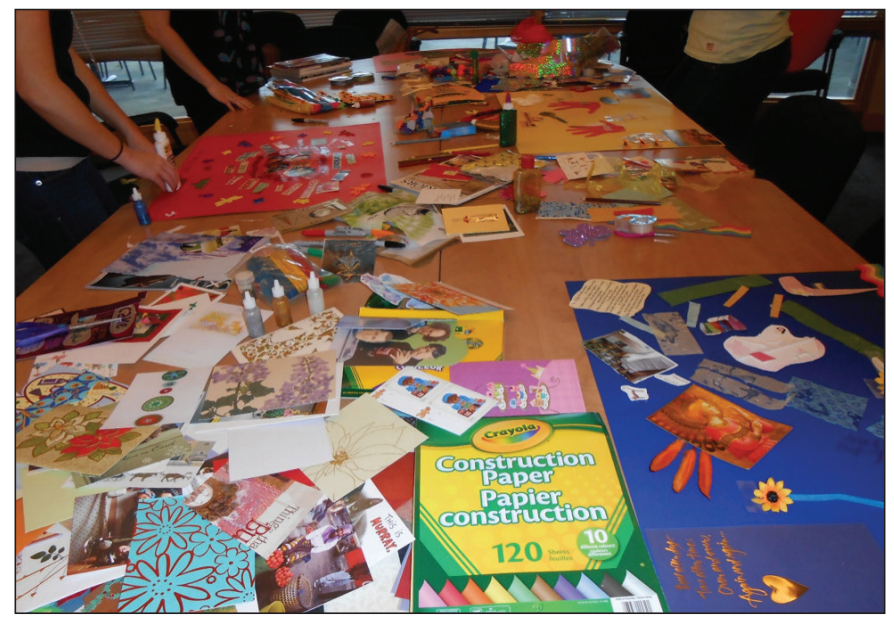

Fig. 1: Collage supplies

One participant created a poster that for her represents what it means to be person-centred within her environment (Fig. 2). This participant has come to realize through our time together that person-centred care also includes the caregiver, and that means taking care of herself. On the collage, she situates herself on the border, observing different ways (healthy nutrition, self-care, spirituality, fun with friends) that she does or could do to take care of herself so that she could be more present with those in her care.

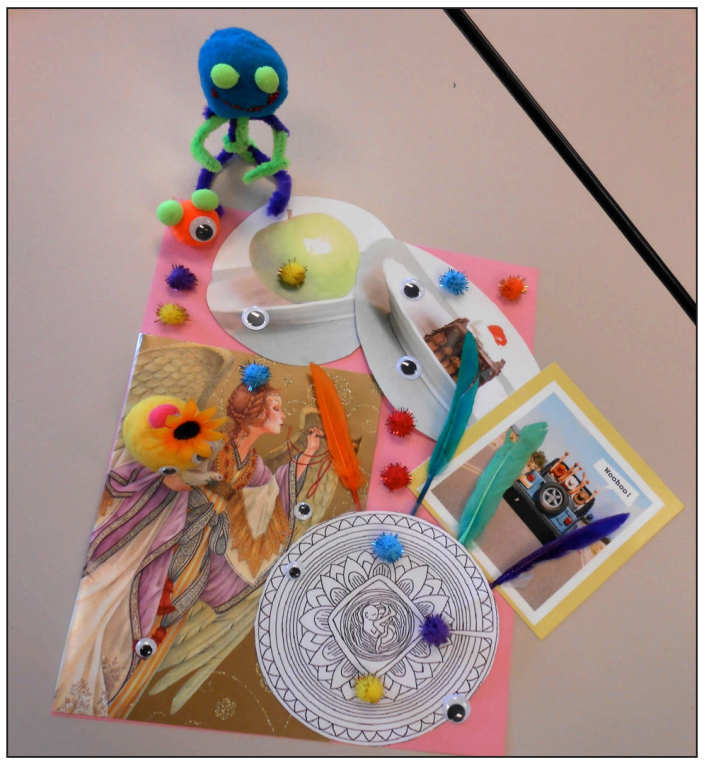

Fig. 2: Collage-What it means to be person-centred 


\section{Co-Creating Art With Music}

For our last session we offer a co-creative art activity (Mantas, 2007; Mantas \& Di Rezze, 2011). By this time in the process the participants are feeling comfortable and safe with one another. This is important, as this co-creative activity calls upon collaboration and trust of group members with one another. Participants are asked to write a question on the focus of the inquiry that they would like to shed more light on for themselves.

Jasna recalls her own experience when she was first introduced to this activity in a workshop conducted by her colleague Kathy Mantas:

As soon as we had our respective questions/ideas written down, Kathy instructed us to turn the paper over, not to share the written notation with anyone, and to listen and move the crayons to the music that she had started to play.

I allowed the music to enter my body and to move the crayons as it did so. As I was settling into drawing the answer to my question, Kathy asked each of us to move one space to the right and to continue listening to the music and drawing. That surprised me, and I experienced a twinge of anxiety that my started drawing would be 'messed up' by someone else who doesn't know what I was looking for. This very brief hiccup disappeared quickly and I once again gave myself over to the music and the drawings as I encountered them. The process moved us around the rectangle of tables, eventually returning me to my own drawing to find it filled in by nine other strange hands. (Schwind \& Mantas, 2012, pp. 11-12)

For one of our participants, the co-created art piece called for the whole group to consider the possibilities of the meaning of the squiggly lines on her paper (Fig. 3). Bennett (2010) observes, "Because the marks are abstract, they can be full of feeling and discernment, and certainly mystery. Both the artist and the viewer create meaning as they look at the marks and allow their own feelings to surface" (p. 27). The owner of the co-created art piece felt safe to think out loud and to ask group members to help her make sense of the co-created art. Group members shared what they were thinking when they were drawing on that sheet of paper, without knowing her question or initial intentions. Possibilities of being at crossroads, being in the centre of the action, surmounting challenges, and despite wanting to be caring, being enclosed within the frame of the system, were some observations her peers offered. Although her peers' input is valuable, the originator of the art piece needs to consider the offerings and explore them through reflection within her own value system, and in light of her question. 


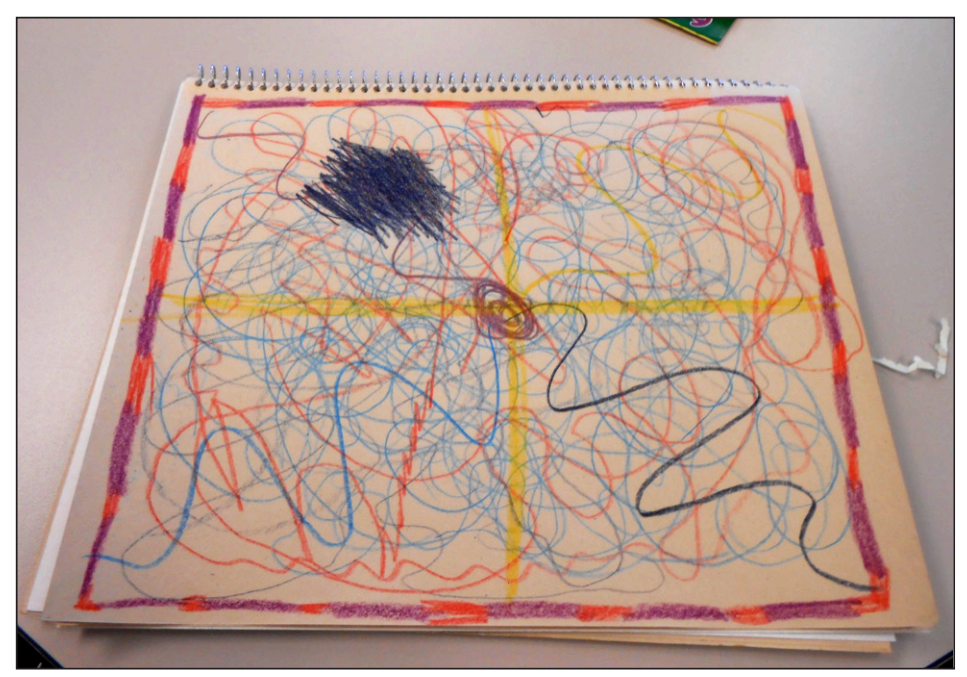

Fig. 3 Co-created art piece

\section{Mindful Walking and Mandala}

In the phase two of our person-centred care inquiry, we added another creative activity, mindful walking and mandala. We were inspired to include a mindfulness activity after having attended an educational retreat with Thich Nhat Hanh, a Buddhist monk who is passionate about introducing mindfulness into education (An Exploration of Mindfulness in Education, August 11-16, 2013 at Brock University, St. Catharines, Canada). In the second phase of the inquiry, this activity became the second-tolast session, and it was done independently, following instructions on our newly created website.

In this activity participants are invited to find a spot at home where they can quiet their mind. When they are ready, they are asked to walk mindfully, noticing their breath in the moment, and feeling how their feet greet the earth. They are asked to do this in a safe place and for as long as they feel comfortable. Upon their return from mindful walking, we suggest participants engage in mindfully colouring a mandala, their own creation or a pre-drawn one (Fig. 4). 


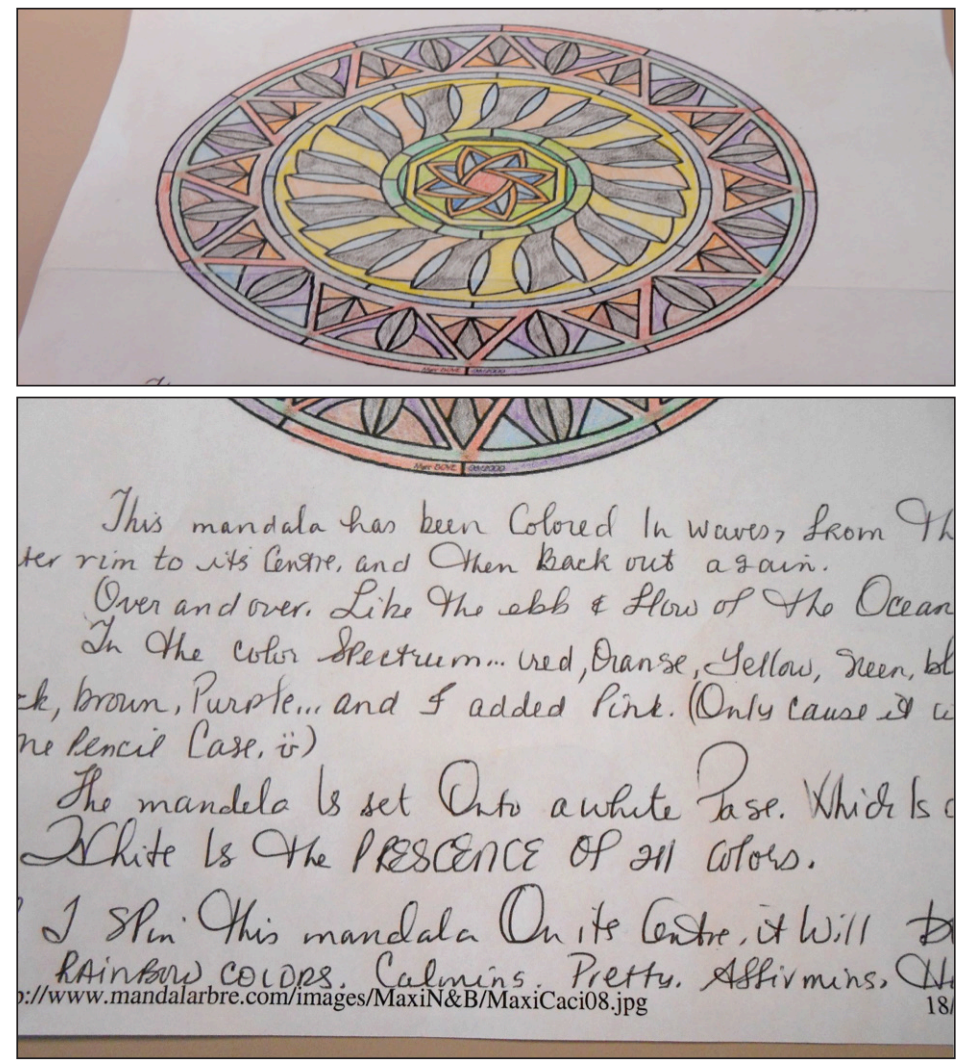

Fig. 4: Mandala with description

Following these activities our participants reflected on their experiences, expressing increased attunement with sounds of nature and peacefulness; one person expressed impatience with prolonged attention on walking. As with each creative activity, we allowed time in the in-person meeting sessions to talk about the experiences, including challenges and "aha" moments, as connected to enacting person-centred care.

\section{Artful Activities in Our Classrooms}

When teaching-learning is understood as an inquiry process, as we do, then we accept the narrative turn (Pinnegar \& Daynes, 2007) that has occurred across disciplines: namely, "acknowledging the subjective, relational, contextual and constitutive nature of inquiry" (Butler-Kisber, 2010, p. 64), using words instead of numbers, focusing on the particular and creating knowledge through multiple ways of knowing that moves beyond the textual boundaries. We understand students as having narrative histories 
that shape their encounters with each other, with us, and with course materials. "It becomes clear that both the heart (through artistic expression) and mind (through theoretical and analytic deliberation) must be stimulated" (Bergum \& Godkin, 2008, p. 606). In order to surface such perspectives, we use research-informed creative activities in our respective classes. We offer examples of how we do this:

Jasna. Creative self-expression is an integral component, not only in my research but also in my work with students. For example, I engage my senior undergraduate nursing students in a Narrative Reflective Process (Schwind, 2008) in order to help them deepen self-awareness and strengthen their personal knowing of who they are as future caregivers. To set a more peaceful and co-operative environment, I start each class with a brief mindful breathing activity (Hahn, 1987/2005; Hassed \& Chambers, 2014; Smalley \& Winston, 2010), and end each class with a short loving-kindness meditation (Salzberg, 1995). As we are together for two semesters, in the fall we begin with ourselves, focusing on the personal life. This means students write stories of their most memorable life experiences, they re-read the stories looking for narrative patterns, and then choose a metaphor that best represents for them their life. Metaphoric reflection follows as described above. In the winter semester, we focus on their professional role by using the metaphor, self-as-instrument of care (Schwind et al., 2012, Schwind, 2016). Towards the end of the term students reflect on the two chosen metaphors, life and professional, and consider how they are similar and different from one another, not only in representation of the images, but also in depiction of chosen colours and themes. At this stage the students are comfortable enough with each other to ponder the possibilities through reflective dialogue. Through such creative engagement students expand and deepen their personal knowing of who they are and what they bring into each interaction with each other and with those in their care.

Gail. I use experiential/creative activities to ensure students are growing in awareness of their assumptions, values, and beliefs as foundational to their worldview and to their actions. This grounds theoretical courses and makes the material relatable for students. Reflection (on and critique) of these fundamental life tenets are skills important to nursing practice and life-changing for the students. I read excerpts from literature about topics relevant to the course, often fiction, and ask students to write responsively about their thoughts, feelings, embodied sensations, and connections to their experiences (Longo \& Lindsay, 2011). Becoming aware of how they pay attention, what stands out for them, what comes easily, or is more challenging, is all information about how they are as persons. In another activity, I ask half the student group to leave the room and instruct the remaining students to play the role of interviewees who only respond to what is asked of them. I meet briefly with the out-of-the room group to 
ask them to interview their partner about what it is like to be at university in nursing school. The interview takes less than five minutes. I then ask the interviewers to come out of the room again and review with them the principles of being present, focused, with an intention for relationship. They then continue the interview. We then discuss what all of them noticed about the two interviews and what happened. This experiential immersion shows them how it feels to create a purposeful caring relationship and the value of including self-awareness in their construction of nursing identity (Lindsay, Kell, Ouellette, \& Westall, 2010). These activities are processes that are congruent with the course learning outcomes and teach students to reconstruct their experience for learning.

\section{How Artful Inquiry Matters to Research-Informed Nursing Education}

As narrative inquirers, we move between teaching-learning, inquiry, and practice as mutually informing and as an ontological stance. Being committed to artful inquiry leads us to start our courses with creative experiential activities before reviewing received theoretical content. We believe that this grounds students in their experiences, relates the course material to what is known, and encourages them to become aware of their thinking processes, witnessing themselves as learners taking up new material. Students are given opportunities to artfully inquire into their experiences and academic resources to be in a position of awareness, generate new options, and discern consequences for actions taken. As students experience how it matters to be listened to attentively, to have a witness, to hear themselves work through an issue aloud, they can empathize with people in their care who face static routines and acontextual practices of many organizations. Bringing together personal, ethical, and aesthetic knowing (Carper, 1978; Chinn \& Kramer, 2008), students build narrative competence, which Corbally and Grant (2016) define as "a finessed, ethically-charged respect for human lived and storied experience" (p. 7). These authors are concerned with how "the dominant narratives of institutional psychiatry trap users in stories told about them that neither accord with their lived experiences nor are respectful to those experiences" (p. 8). As our co-participants told us, there is the system as given, the history of "how we've always done it," the team expectations, and then there are personal values, professional intentions, and self-definition of what matters in nursing care. We want students and nurses to be aware of the difference and to make choices about how to be in a relationship and what actions to take with others who need care. Students and nurses told us that by engaging in artful activities their reflection on practice was enhanced through the tangible manifestation of their thinking. For example, one participant commented, "Now I am reflecting before a situation and afterwards, thinking of everything as a whole and my role in it"; another person observed, "We are all sharing with each other and so bettering each other." 
We invite students to experience themselves as experts of their own lives with authorship of their story as a way to illuminate how this could be significant for people in their care. We consistently surface meta-cognition by asking questions such as: Why are we doing that and doing it in this way? How does this teaching-learning activity mirror patient care situations? What is coming into my awareness in response to this situation? How does my autobiography inform my professional role? How does the humanity I share with others connect us in a place of vulnerability? How does any of this change how I am as a nurse?

In keeping with the evaluative criteria of AINI, our work is transferable to different groups of teachers, learners, practitioners, and researchers. "It is through rigorous and reflective practice that theoretical knowledge and lived experiences can be embodied, made meaningful and thus contribute to the generation of new understandings" (Barbour, 2011, p. 86). Likewise, our hope is that students transfer artful inquiry from their education to their professional practice to be even more than intellectually responsible- to be artfully transformative. Thus, the next steps to exploration of artful inquiry would be to engage novice practitioners who were (as students) exposed to creative educational approaches, such as we describe above, to learn how these are lived out in their clinical environments.

\section{References}

Barbour, K. (2011). Dancing across the page: Narrative and embodied ways of knowing. Chicago: Intellect, The University of Chicago Press.

Bennett, C. (2010). The confident creative: Drawing to free the hand and mind. Forres, Scotland, UK: Findhorn Press.

Bergum, V., \& Godkin, D. (2008). Nursing research and the transformative value of art. In J. G. Knowles \& A. L. Cole (Eds.), Handbook of the arts in qualitative research (pp. 603-612). Thousand Oaks, CA: Sage Publications, Inc.

Bhattacharaya, K. (2008). Voices lost and found: Using found poetry in qualitative research. In Melisa Cahnmann-Taylor \& Richard Siegesmund (Eds.), Arts-based research in education: Foundations for practice (pp. 83-88).
Butler-Kisber, L. (2002). Artful portrayals in qualitative inquiry: The road to found poetry and beyond. Alberta Journal of Educational Research, 48(3), 1-9.

Butler-Kisber, L. (2010). Qualitative inquiry: Thematic, narrative and arts-informed perspectives. Thousand Oaks, CA: Sage.

Carper, B.A. (1978). Fundamental patterns of knowing in nursing. Advances in Nursing Science, 1, 13-23.

Chinn, P. L., \& Kramer, M. K. (2008). Integrated theory and knowledge development in nursing. St. Louis, MO: Mosby Elsevier.

Clandinin, D. J., \& Connelly, F. M. (1998). Personal experience methods. In N. K. Denzin \& Y. S. Lincoln (Eds.), Collecting and interpreting qualitative materials (pp. 150-177). Thousand Oaks, CA: Sage. 
Connelly, F. M., \& Clandinin, D. J. (1990). Stories of experience and narrative inquiry. Educational Researcher, June-July, 2-14.

Connelly, F. M., \& Clandinin, D. J. (2006). Narrative inquiry. In J. L. Green, G. Camilli, P. B. Elmore, A. Skukauskaite, \& E. Grace (Eds.), Handbook of complementary methods in education research (pp. 477-487). Washington, DC: Lawrence Erlbaum Associates, Inc.

Corbally, M., \& Grant, A. (2016). Narrative competence: A neglected area in undergraduate curricula. Nurse Education Today, 36, 7-9.

Dewey, J. (1933/1998). How we think. Boston: Houghton Mifflin.

Dewey, J. (1938). Experience and education. New York: Macmillan.

Faulkner, S. L. (2009). Poetry as method: Reporting research through verse. Walnut Creek, CA: Left Coast Press.

Hahn, T. N. (1987/2005). Being peace. Berkley, CA: Parallax Press.

Hassed, C., \& Chambers, R. (2014). Mindful learning: Reduce stress and improve brain performance for effective learning. Auckland, NZ: Exile Publishing Pty. Ltd.

Lindsay, G. (2006). Constructing a nursing identity: Reflecting on and reconstructing experience. Reflective Practice, 7(1), 59-72.

Lindsay, G. (2008). Thinking narratively: Artificial persons in nursing and healthcare. Nurse Education Today, 28(3), 348-353.

Lindsay, G. (2011). Patterns of inquiry: Curriculum as life experience. Nursing Science Quarterly, 23(4), 237-244.

Lindsay, G., in collaboration with J. W. D. Bjarnason. (2005). Pioneers past and present: Curriculum insights from stories that link through generations. McGill Journal of Education: Narrative Perspectives in Education, 40(1), 189-199.

Lindsay, G., Kell, L., Ouellette, J., \& Westall, H. (2010). Using "I" in scholarly writing: How does reflecting on experience matter? Reflective Practice, 11(3), 271-283.
Lindsay, G., \& Schwind, J. K. (2014a) Arts-informed narrative inquiry into nurse-teachers' legacy for the next generation. Reflective Practice, 16(2), 195-205. doi:10.1080/14623943.2014.9 92405

Lindsay, G., \& Schwind, J.K. (2014b). Artsinformed narrative Inquiry: Constructing person-centred care. Retrieved from www. theartofexperience.ca

Lindsay, G., \& Schwind, J. K. (2015). Arts-informed narrative inquiry as a practice development methodology in mental health. International Practice Development Journal, 5(1). Retrieved from http://www.fons.org/library/journal. aspx

Lindsay, G., \& Smith, F. (2003). Narrative inquiry in a nursing practicum. Nursing Inquiry, 10(2), 121-129.

Longo, F., \& Lindsay, G. (2011). Knowing nursing through inquiry: Engaging students in knowledge creation. Journal of Nursing Education, 50(12), 703-705.

Mantas, K. (2007). Meeting mermaids: Co-creating images and process in inquiry. In Knowles, G., Luciani, T., Cole, A., \& Neilsen, L. (Eds.), The art of visual inquiry (pp. 153-166). Halifax, NS: Backalong Books.

Mantas, K., \& Di Rezze, G. (2011). On becoming 'wide-awake': Artful re-search and co-creative process as teacher development. Arts and Learning (Special Journal Edition hosted by: International Journal of Education \& the Arts).

Pinnegar, S., \& Daynes, J. (2007). Locating narrative inquiry historically: Thematics in the turn to narrative. In D.J. Clandinin (Ed.), Handbook of narrative inquiry: Mapping a methodology (pp. 3-75). Thousand Oaks, CA: Sage.

Polanyi, M. (1958/1974). Personal knowledge: Towards a post-critical philosophy. Chicago: The University of Chicago Press.

Polanyi, M. (1966/2009). The tacit dimension. Chicago: University of Chicago Press.

Prendergast, M. (2006). Found poetry as literature review: Research poems on audience and performance. Qualitative Inquiry, 12(2), 369-388. 
Registered Nurses Association of Ontario. (2015). Person and Family-Centred Care. Best Practice Guideline. Toronto, ON: Author.

Salzberg, S. (1995). Loving-kindness: The revolutionary art of happiness. Boston: Shambhala Publications, Inc.

Schwind, J. K. (2003). Reflective process in the study of illness stories as experienced by three nurse-teachers. Reflective Practice, 4(1), 19-32.

Schwind, J. K. (2008). Accessing humanness: From experience to research, from classroom to praxis. In J. K. Schwind \& G. M. Lindsay (Eds.), From experience to relationships: Reconstructing ourselves in education and healthcare (pp. 77-94). Charlotte, NC: Information Age Publishing Inc.

Schwind, J. K. (2014). Narrative reflective process: Giving voice to experience of illness. In C. McLean (Ed.), Creative arts in humane medicine (pp. 125-140). Edmonton, AB: Brush Education Inc.

Schwind, J. K. (2016). Narrative reflective process: A creative experiential path to personal-knowing in teaching-learning scholarship. In J. Gingras, P. Robinson, J. Waddell, \& L. Cooper (Eds.), Teaching as scholarship: Preparing students for professional practice in community services (pp. 137-154). Waterloo, ON: Wilfrid Laurier University Press.

Schwind, J. K., Cameron, D., Franks, J., Graham, C., \& Robinson, T. (2012). Engaging in narrative reflective process to fine tune self-as-Instrument of care. Reflective Practice, 13(2), 223-235. doi:10.1080/14623943.2011.626030
Schwind, J. K., Fredericks, S., Metersky, K., \& Gaudite Porzuczek, V. (2015). What can be learned from patient stories about living with the chronicity of heart illness? A narrative inquiry. Contemporary Nurse Journal, 1-32. doi:10.1080/10376178.2015.1089179

Schwind, J.K., Lindsay, G., Coffey, S., Morrison, D., \& Mildon, B. (2014). Opening the black-box of person-centred care: An arts-informed narrative inquiry into mental health education and practice. Nurse Education Today, Special Issue NET 2013, 34(8), 1167-1171. doi:10.1016/j. nedt.2014.04.010

Schwind, J. K., \& Mantas, K. (2012). Coconstructing holistic knowing through reflective dialogues on a co-creative artmaking experience. The International Journal of Holistic Education, 1(1), 9-22.

Schwind, J. K., Santa Mina, E., Metersky, K., \& Patterson, E. (2015). Using the narrative reflective process to explore how students learn about caring in their nursing program: An arts-informed Narrative Inquiry. Reflective Practice, 16(3), 390-402. doi:10.1080/1462394 3.2015.1052385

Smalley, S. L., \& Winston, D. (2010). Fully present: The science, art, and practice of mindfulness. Philadelphia: Da Capo Press. 


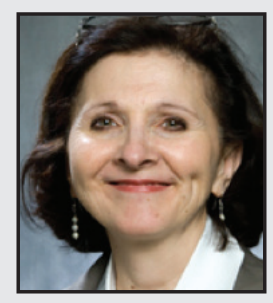

Jasna Krmpotić Schwind is Associate Professor of Nursing at Ryerson University, Toronto, Canada. Her program of research, by means of arts-informed narrative inquiry, focuses on reconstruction of experience of personal and professional self within professional and therapeutic relationships in education and practice. To this end, she developed the Narrative Reflective Process (NRP), which is both a data-collection tool as well as a professional development instrument. This creative selfexpression method includes storytelling, metaphors, drawing, creative writing, and reflective dialogue. In her scholarship of teaching-learning, Dr. Schwind uses NRP to mentor and support students and peers.

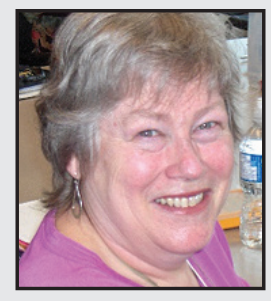

Gail M. Lindsay is an Associate Professor in the Faculty of Health Sciences at the University of Ontario Institute of Technology. She teaches qualitative research at the graduate level and in the undergraduate nursing program. Her research program focuses on construction of identity and knowledge of students and practitioners through reconstruction of experience and use of arts-informed processes. The principle that who you are as a person is who you are as a practitioner is foundational, illuminating how the personal and social are mutually informing. Her inquiries, connecting research-theory-practice, show how people author their lives. 